\title{
Indigenous Wisdom of Farm Women in Grain Storage
}

\author{
Anju Manocha \\ Lecturer, GCG, Panchkula \\ E-mail: anjumanocha@gmail.com
}

Kanchan Monga

Lecturer, GCG, Panchkula

\begin{abstract}
Received: February 6, 2013 Accepted: March 11, 2013 Published: December 25, 2013
doi:10.5296/jee.v4i2.4959ＵRL: http://dx.doi.org/10.5296/jee.v4i2.4959
\end{abstract}

\begin{abstract}
Farmers store the produce for two reasons; for home consumption and marketing. Farmers may not accept improvements which incur costs when storing primarily for home consumption. Most developing countries are in the tropics, often in areas of high rainfall and humidity. These conditions are ideal for the development of micro-organisms and insects which cause high levels of deterioration of crops in store. Food losses during storage are the result of biological, chemical or physical damage. In earlier times various indigenous items and methods were used for storage of household items including food items, clothing and bedding etc. The shelf life or storage span of items was increased using readily available and low cost items like ash, sand and plants. Present investigation was carried out in selected villages of Panchkula district of Haryana State by contacting 240 respondents through one to one interaction and group discussion along with participatory rural appraisal technique. The technologies used by respondents for storing grains were documented. The results revealed that neem, camphor, ash, table salt, turmeric powder etc. were the common methods adopted by majority of the respondents for storing the grainsalthough majority of them were not aware of the reasons or qualities of these materials and were using them as age old wisdom. Temperature maintenance was another technique adopted by respondents as the moisture content of grains was checked by cracking them under teeth. So it can be concluded that many of the indigenous practices find credibility even in today's period. Moreover, their user-friendly approach, local availability associated with scientific reasoning provides enjoyment and satisfaction to the users. It must therefore be encouraged to use only those eco-friendly practices that are known to be both safe and effective. These practices must be
\end{abstract}


modified to make them more efficient for further transfer to the end users in the future.

Keywords: Indiginous, Grain storage 


\section{Introduction}

In view of fast and time bound routine of families which resulted due to more and more participation of females in economic function of family, storage of perishable as well as semi-perishable items for ready use by family has become all the more important. But if they are not stored properly, they may spoil; their usability may decrease along with financial loss. So the duty of home maker to use various containers, methods and products while storing household items has increased. In earlier times also various indigenous items and methods were used for storage of household items including food items, clothing and bedding etc. The shelf life or storage span of items was increased using readily available and low cost items like ash, sand and plants. Such practices are being followed even now as these are not only user-friendly but also increase shelf life of items. Along with solving the purpose for which they are used, these practices are satisfying, eco-friendly and enjoyable as no chemical substances are used. Only natural and locally available resources are exploited for their qualities. Present investigation was carried out with the objective to document and promote the scientifically correct traditional practices used by rural homemakers during storage of household items. Indigenous knowledge has two powerful advantages over scientific knowledge like it has little or no cost, and is readily available. It is the knowledge, skill or technology gathered by local masses during direct interaction of human beings with the environment. Women folk have accumulated knowledge of household practices over generations by observation, experimentation and by handling of various commodities. Certain practices are unique to a given culture of a society and vary between countries, regions, villages and even communities. Indigenous practices are passed on from generations and are an outcome of elder's wisdom and experience as a result of their close contact and deep knowledge of their environment. These reasons imply that indigenous knowledge is eco friendly and safe both to man and his environment. It is estimated that $60-70 \%$ of food grains produced in the country is stored at home level in indigenous structures ranging from bamboo baskets to mud structures, gunny bags and modern bins. Indigenous Knowledge is the knowledge which has unfolded within the group and is transferred from one generation to another. Proper storage of food grains is necessary to prevent spoilage, increase keeping quality and to avoid wastage of precious resources and money. Good storage facilities are important to the farmers all over the world. Food security till the forthcoming harvest is also ensured by good storage practices. Along with this, the farmer is not compelled to sell the harvest or commodities during the period when market is already flooded with the produce. By doing so they help to reduce the storage losses which are greatest when compared to the ones in the field before and during storage.

\section{Methodology}

The study was undertaken in selected villages of Panchkula district of Haryana State. These villages were sampled from amongst all the four blocks of district. Two villages from each block of district accounting for a total of eight villages namely Kot and Behar from Barwala block, Garikotaha and Haripur from Raipurani block, Chowki and Manakpur from Pinjore block and Mandana and Bunga from Morni block. Thirty farm women were selected randomly from each of the villages. A total of 240 rural women were selected from all the four blocks, 
comprising of 60 respondents from each block. The information on their knowledge of storage practices was gathered with the help of pretested schedule and group discussions. Participatory Rural Appraisal technique was adopted to collect information about the storage practices prevalent in that area. By contacting the respondents through one to one interaction and group discussion along with participatory rural appraisal technique, the technologies used by respondents were documented.

\section{Results and Discussion}

Farmers store the produce for two reasons; for home consumption and marketing. Farmers may not accept improvements which incur costs when storing primarily for home consumption. In many cases, these need only small improvements to make the difference between simply having enough for subsistence and creating a surplus for sale. Most developing countries are in the tropics, often in areas of high rainfall and humidity. These conditions are ideal for the development of micro-organisms and insects which cause high levels of deterioration of crops in store. Food losses during storage are the result of biological, chemical or physical damage. In order to reduce the amount of food grains lost, the environment in the store needs to be controlled so as to lower the possibility of:

- biological damage by insects, rodents and micro-organisms and

- chemical damage through rancidity development and flavour changes, etc.

- physical damage through crushing, breaking, etc.

Good storage thus involves controlling the factors, like temperature, moisture, light, pests and hygiene.

\subsection{Temperature}

The temperature within a store is affected by the sun, the cooling effect of radiation from the store, outside air temperature, heat generated by the respiration of both the food in store and any insect pest present. Most of the micro-organisms thrive between 10 and $60^{\circ} \mathrm{C}$ temperature where as insects between 16 and $45^{\circ}$ centigrade. Normally, in tropics and subtropics, storage temperature lies between 25 and $35^{\circ} \mathrm{C}$ which is favourable for the survival of the micro-organisms and insects. Direct temperature control is not usually possible, so other measures, particularly reducing the moisture content of the stored produce, are necessary. Running is a method of controlling insect pests involving heat. The produce will be laid out in a thin layer in the hot sunlight. At high temperatures' (40 to $45 \mathrm{o} \mathrm{C}$ ) the insect pests tend to leave the grain. It should be noted, however, that running does not always destroy eggs or larvae. Improper maintenance of storage temperature can result in biological and chemical damage to the food stuff being stored. Examples include the loss of germination ability in seed materials and the accumulation of sugars in some commodities which need relatively low storage temperatures. Temperature also controls chemical damage. The speed of chemical change in a food depends upon the temperature and the food's moisture content. A $10^{\circ} \mathrm{C}$ rise in temperature causes an approximately two-fold increase in the rate of reaction. Thus, cold storage will retard such changes as fat oxidation and vitamin loss. Many dried 
food grains benefit from even a small reduction in their storage temperature, and cool and dry conditions can greatly reduce the rate of development of brown discolouration and offflavours. Physical damage involves melting of fats in the products at high temperatures and crystallization of sugars in sweet foods at low temperatures.

\subsection{Moisture}

All micro-organisms, including moulds, require moisture to survive and multiply. If the moisture content in a product that is to be stored is low, micro-organisms will be unable to grow, provided that the moisture inside the storage structure is also kept low. Moisture should therefore, be prevented from entering the store. All materials that have been dried will try to come back into equilibrium with the climate around them. In tropical countries this usually means absorbing moisture. The moisture level below which micro-organisms cannot grow is referred to as the safe moisture content.

The storage practices for various commodities and the possible mode of action is discussed as follows.

\subsubsection{Storage of Pulses by Common Salt}

Common table salt was used to store pulses for a period of 6-8 months. In this practice about $200 \mathrm{gm}$. of salt is mixed manually in one $\mathrm{kg}$. of pulse. Due to this practice, insects were kept away from the stored grains. As salt had abrasive action on skin of insects thereby preventing their movement inside the storage containers and as a result their growth in the storage box was inhibited. This practice was perceived to be moderately effective and affordable in cost. Karthikeyan, C. (2008) too reported that farmers used common ingredient, table salt, in red gram grains for storage in their house. Salt has hygroscopic and insecticidal property which helps in keeping the grain dry by absorbing the moisture thus avoiding spoilage and hence aid in safe storage. Gupta et.al. (2010).

\subsubsection{Neem Oil in Seed Storage}

Majority of respondents practiced technologies that usually do not require high degree of technical skill and much cost. One such practice was use of neem oil which was manually applied on pulses to coat every grain uniformly. Neem oil acted as repellent to many insects such as beetles, moths and figs. Neem oil attacks insects at the egg stage itself thereby saving the legumes. Several properties of neem like repellence, feeding and ovi-positional deterrence, growth inhibition etc, made it popular storage item. Some respondents mixed mustard or any other cooking oil in 1:1 ratio with the neem oil for treating the pulses against storage pest. Moong dal was stored by smearing it with oil as reported by Sreedevi., B (1994). Oil makes the seed surface slippery thereby preventing the insect to breed or crawl on the grain.

\subsubsection{Storage of Wheat}

As neem oil was used for pulses, dry neem leaves were put in cloth bags, by most of the respondents, which were placed at the top, middle and bottom of the container. Anti-parasitic, sterilant, insect and pest repellent, anti-fungal and non-toxic qualities of neem prevent the wheat grains from spoilage. Matchboxes were also used by respondents in the similar fashion 
because of phosphorus in them which is anti-repellent in nature. Another method adopted by respondents was mixing of cow dung ash in wheat as it is desiccative and insecticidal in nature. A few respondents used turmeric powder at the bottom of container, in the middle and top of container. Turmeric has pesticidal, insecticidal and antifungal properties. Although storing grains in bags is not very ideal, it is one of the common modes of storage. Often, the bags themselves serve as a source of infestation. Hence, it is advisable to use new bags or put old sacks in boiling water and dry them in bright sun light before use. Bags of uniform size and weight should be chosen. If there are any holes they should be mended. Fill insect free, clean, cool and dry grain in the bags. Each kind of grain should be put in a separate bag. The mouth of the filled bags should be stitched. In case of machine stitching, five stitches in 2.5 $\mathrm{cm}$ should be used. The results are in concurrence with those of Dhaliwal (2010) who reported that use of neem leaves, husk, salt, camphor was practised either singly or in combination to prevent food grains from insect infestation.

\subsubsection{Storage of Rice}

Majority of the respondents mixed turmeric powder with the rice grains before storing them in containers or jute bags. Some of the respondents applied mixture of mustard oil and turmeric powder on rice grains. Other methods used were putting cloves of garlic in layers of rice as garlic. Growth of insects, mites, molds and other microbes are at their highest levels in 68-95 F range. Sethi, (2000) also found that the most common method for storage of grains for household consumption was in gunny bags $(33.3 \%)$ followed by local or traditional method using sand, neem leavesand match sticks etc.

\subsubsection{Use of Camphor}

Use of camphor for both the cereals as well as pulses repels a wide range of storage pests. Hence majority of respondents placed $1 \mathrm{gm}$. of camphor piece per $5 \mathrm{~kg}$. of grain in the jute gunny bag. This practice of keeping camphor inside the storage bag repelled the pests due to the strong odour emanated from camphor. Short term storage of grains upto 3 months was possible with this traditional storage method. For subsequent storage, the grains were sun dried and fresh camphor was kept in the bag.

\subsubsection{Use of Ash}

Indigenously, grains were stored in earthen pots. For safe storage of grains, grains were filled in earthen pots to its $3 / 4$ volume and rest 1.4 volumes being filled by wood or cow-dung ash. By doing so, majority of the respondents felt that wide range of storage pests like pulse beetles and fig moth could be controlled for 6-8 months. If grains are to stored for a longer period, then after 6 months the grains and pots are sun-dried and again filled with fresh ash. It has been reported that farmers in Rajasthan also use ash to prevent attack of storage pests. It was reported from Kandi areas of Punjab that premixing of seed with sufficient quantity of ash was commonly practised for storing grains. Dhaliwal (2010) and Balasubrananian (1992) Rubbing ash or dry sand on green gram seeds for their safe storage was also reported. The scientific basis of using ash is that ash contains silica which along with being harmful to insects is also harmful to insect pests. 


\subsubsection{Maintaining Temperature}

Majority of the respondents used to store grains during night or morning hours. They had the belief that the grains stored in the morning or at night were less attacked by storage pests. Although they were not aware of the logic behind this but it has a basis, as it acted as controlling temperature favourable for growth of pests. Mahindera Rai et. al. in their study on basic concepts of post harvest storage technology reported that an important consideration while storing the food grains is temperature, oxygen, carbon-dioxide concentration. For every $5 \%$ of decrease in storage temperature, longevity of grain is doubled.

So it can be concluded that many of the indigenous practices find credibility even in today's period. Moreover, their user-friendly approach, local availability associated with scientific reasoning provides enjoyment and satisfaction to the users. It must therefore be encouraged to use only those eco-friendly practices that are known to be both safe and effective. These practices must be modified to make them more efficient for further transfer to the end users in the future. There is an urgent need to follow scientific storage practices to maintain the keeping quality of food products and other commodities at domestic level so as to derive optimum nutrition from them. These practices vary according to the materials and methods used during storage. As it is the women folk who are guarding or taking care of the produce on the farm which may either be used in households or used for commercial purposes. So they should be encouraged to use safe, effective and eco-friendly practices. Moreover as these practices are passed on from generation to generation, it is all the way more important to modify these practices in terms of their effectiveness and user friendly property.

\subsubsection{Tips for Storage of Food Grains}

This has been reported that up to 10 million tonnes of food-grains are lost each year in India through faulty storage techniques. If saved, it would have been more than enough to meet any world food deficit. It has been estimated that 10 percent loss in storage may be sufficient enough to feed 72 million people. The large stocks of grain in storage pose various problems which are unique and quite different from those of smaller lots. Therefore, adequate attention must be paid in the large scale storage of food-grains. To minimize the storage losses some practices for large scale storage of food grains has been developed.

1. The grains must be checked before harvest in the field itself to ensure that the grains are free from insects and diseases.

2. The harvesting and transporting implements must be cleaned before a new crop is harvested.

3. The grains must be harvested and threshed to avoid any breakage of grains, because broken grain will not store well.

4. The threshing yards which are free from insect infestation should be used.

5. Before storage the grains should be cleaned and graded. Straw, weed seeds and dirt in the unclean grains not only decrease the value of food grains but also cause the grains to deteriorate during storage. 
6. No food-grains with moisture content higher than the safe acceptable level should be accepted for storage. As the moist grain gives off more heat and moisture, which encourages build up of insect population and mould growth and development of hot spots in bulk grains, the moist grains should be properly dried before storage.

7. The grains should be spread over plastic sheets or cemented floor while drying, otherwise it will pick up the moisture from the ground. The grains should be kept dry and cool between the time of harvest and storage.

\section{References}

Balasubramanian, P. (1992). Indigenous knowledge use in dry lands: An exploratory study. M.Sc. Thesis. Tamil Nadu Agricultural University, Coimbatore.

Dhaliwal, R. K., \& Singh, Gurdeep. (2010). Traditional food grain storage practices of Punjab. Indian Journal of Traditional Knowledge, 9(3), 526-530.

Gupta, Manju., Jain, Simple., \& Mandowara, Depika. (2010). User friendly storage practices followed by rural women of Rajasthan.

Karthikeyan, C., Veeraragavathatham, D., Karpagam, D., \& Firdouse, Ayisha, S. (2009). Traditional Storage Practices. Indian Journal of Traditional Knowledge, 8(4), 564-568.

Mahindera, Rai., Mehta, R. K., \& Tiwari, T. C. (2012). International Symposium on Grain Storage. Organised by Indian Society of Agricultural Engineers and GBPUAT, Pantnagar.

Nagnur, Shobha, Channal, Geeta, \& Channamma, N. (2006). Indigenous grain structures and methods of storage. Indian Journal of Traditional Knowledge, 5(1), 114-117.

Sethi, Nishi, \& Malaviya, Achla. (2000). Scientific rationality of indigenous grain storage practices practised by rural women. Indian Journal of Agricultural Research, 34(3), 188-190.

Sreedevi, B. (1994). Indigenous technical knowledge in farming and agricultural research. Kisan World, 21, 11-12. 